\title{
Preliminary Studies on the Antibacterial Mechanism of a New Plant-Derived Compound, 7-Methoxycoumarin, Against Ralstonia solanacearum
}

\author{
Songting Hant, Liang Yangt, Yao Wang, Yuao Ran, Shili Li and Wei Ding* \\ Laboratory of Natural Products Pesticides, College of Plant Protection, Southwest University, Chongqing, China
}

Ralstonia solanacearum ( $R$. solanacearum) is one of the most devastating plant bacterial pathogens and leads to serious economic losses in crops worldwide. In this study, the antibacterial mechanism of 7-methoxycoumarin, a new coumarin

OPEN ACCESS

Edited by:

Ponmurugan Karuppiah

King Saud University, Saudi Arabia

Reviewed by:

Melanie J. Filiatrault,

Agricultural Research Service,

United States Department

of Agriculture, United States

Vijai Singh,

Indrashil University, India

*Correspondence: Wei Ding

dwing@swu.edu.cn

Specialty section:

This article was submitted to Antimicrobials, Resistance,

and Chemotherapy,

a section of the journal

Frontiers in Microbiology

Received: 20 April 2021

Accepted: 19 July 2021

Published: 06 August 2021

Citation:

Han S, Yang L, Wang Y, Ran Y, Li S and Ding W (2021) Preliminary

Studies on the Antibacterial Mechanism of a New Plant-Derived Compound, 7-Methoxycoumarin Against Ralstonia solanacearum.

Front. Microbiol. 12:697911. doi: 10.3389/fmicb.2021.697911 antibiotic, was preliminarily investigated by the observation of symptoms and physical and biochemical analyses. The results showed that 7-methoxycoumarin significantly suppressed bacterial growth of $R$. solanacearum, with the minimum inhibitory concentration $(\mathrm{MIC})$ and the minimum bactericidal concentration $(\mathrm{MBC})$ values of 75 and $175 \mathrm{mg} / \mathrm{L}$, respectively. Electron microscopy observations showed that the bacterial cell membrane was destroyed after 7-methoxycoumarin treatment. Biofilm formation of $R$. solanacearum was significantly suppressed by 7 -methoxycoumarin at concentrations ranging from 25 to $100 \mathrm{mg} / \mathrm{L}$. Furthermore, virulence-associated genes epsE, hrpG, and popA of $R$. solanacearum were significantly inhibited by 7 -methoxycoumarin. The application of 7-methoxycoumarin effectively suppressed tobacco bacterial wilt progress in pot experiments, with relative control efficiencies of 83.61, 68.78, and $58.11 \%$ at 6,8 , and 10 days post inoculation, respectively.

Keywords: coumarins, R. solanacearum, antibacterial activity, tobacco bacterial wilt, membrane lysis, 7-methoxycoumarin

\section{INTRODUCTION}

Tobacco bacterial wilt is a destructive bacterial soil-borne disease caused by Ralstonia solanacearum (R. solanacearum) that has an enormous impact on tobacco production and causes large annual economic losses (Swanson et al., 2005; Wu et al., 2015; Jiang et al., 2017). R. solanacearum invades host plants through root wounds, grows to high cell densities in the plant host and produces a high mass of extracellular polysaccharides, resulting in hindrance of water transportation in the plant, host wilting and death (Zeid, 2002; Li et al., 2017). Currently, the control methods of bacterial wilt include biological, chemical, cultural and integrated management (Bai et al., 2016; Cai et al., 2018). Pesticides discovered and produced by the agrochemical industry exert powerful effects for disease control management. However, long-term unreasonable use of bactericides leads to serious environmental problems inducing successive development of pesticideresistant pathogens, disrupting the soil ecological balance, and causing the issue of environmental 
safety (Fujiwara et al., 2011; Gutiérrez-Barranquero et al., 2013). Developing plant varieties with resistance to bacterial wilt is considered to be the most environmentally friendly, economical, and effective method of disease control. However, many crops with the resistance to bacterial wilt show a low yield and poor quality (Shew et al., 2019). The breeding time of resistant varieties is long, and it is difficult to meet the demand for these crops. Therefore, exploring and developing novel, eco-friendly, and efficient bactericides is important for bacterial wilt control.

Biopesticides are regarded as remarkable alternatives to classic agrochemicals, and have played a crucial role in plant disease control. Renewable plant bioresources contain a variety of plantderived compounds (PDCs) (Hassan et al., 2009; Li et al., 2014; Cai et al., 2020). Recent studies have proven that these compounds can be used as antibacterial agents to suppress soil borne pathogens and promote plant growth (Paret et al., 2010; Abo-Elyousr et al., 2014). Certain PDCs including DIMBOA, lansiumamide $\mathrm{B}$ and protocatechualdehyde, suppress the growth of $R$. solanacearum, resulting in the control of plant bacterial wilt (Li et al., 2014, 2016; Guo et al., 2016). 4-Methoxy-cinnamic acid, benzoic acid and trans-4-hydroxycinnamohydroxamic acid are demonstrated to target the type III secretion system and biofilm formation of plant pathogens (Khokhani et al., 2013; Li et al., 2015). Currently, a variety of natural products have been developed as leader compounds to design biopesticides (Yang et al., 2018).

Coumarins are natural secondary metabolites comprised of fused benzene and $\alpha$-pyrone rings produced through the phenylpropanoid pathway and coumarins accumulate in response to infection by plant pathogens (Zeid, 2002; Sun et al., 2014). Coumarins exhibited strong antibacterial activities against both clinical pathogenic bacteria (such as Escherichia coli, Staphylococcus aureus, and Pseudomonas aeruginosa) and plant pathogens (such as $R$. solanacearum, Alternaria alternata, and Botrytis cinerea) (Goy et al., 1993; Souza et al., 2005). Studies have reported that coumarin exhibits strong antibacterial activity against $R$. solanacearum by inducing cell membrane lysis (Chen et al., 2016). The antibacterial activity of coumarins is related to the polarity of the oxygen-containing substituents on the benzene ring. When the $\mathrm{C}-7$ position on the benzene ring has a methoxy functional group, or the C-6 and C8 positions have hydroxyl group substituents, the compound exhibits broad-spectrum antibacterial activity (Kayser and Kolodziej, 1999). Hydroxycoumarins, including umbelliferone, esculetin and daphnetin show strong antibacterial activity against R. solanacearum (Yang et al., 2018). However, the inhibitory activity of methoxycoumarins against $R$. solanacearum remains largely unclear.

In this study, we demonstrated the antibacterial activity of 7-methoxycoumarin against $R$. solanacearum. The effects of 7methoxycoumarin on the ultrastructure of bacterial cells and the leakage of intracellular constituents, as well as the activity of biofilm formation and swimming activity, were examined to understand the mechanism of action of plant-derived coumarins against $R$. solanacearum. Furthermore, the control efficiency of 7-methoxycoumarin on tobacco bacterial wilt was evaluated in pot experiments.

\section{MATERIALS AND METHODS}

\section{Bacterial Cultures and Compounds}

The R. solanacearum (CQPS-1) used in this study was collected by the Laboratory of Natural Products Pesticides and was isolated from an infected tobacco plant in Chongqing, China (Liu et al., 2017). R. solanacearum was grown at $30^{\circ} \mathrm{C}$ on a $\mathrm{BG}$ medium (Boucher et al., 1985).

The 7-methoxycoumarin (HPLC $\geq 98 \%$ ) used in the study was purchased from Shanghai Yuanye Bio-Technology Co., Ltd. (Shanghai, China). This compound was dissolved in dimethyl sulfoxide (DMSO) and prepared at a final concentration of $10 \mathrm{mg} / \mathrm{mL}$. Then, the dissolved compound was added to BG or BG agar medium to prepare compound suspensions of different concentrations, and negative control was treated with the same concentration of DMSO solvent ( $0.4 \%$ final concentration).

\section{Determination of MIC and MBC}

The minimum inhibitory concentration (MIC) and minimum bactericidal concentration (MBC) were determined using the agar dilution method with a series of final concentrations ranging from 25 to $200 \mathrm{mg} / \mathrm{L}$, as previously described with minor modifications (Li et al., 2014). Briefly, overnight-cultured $R$. solanacearum suspension $\left(10^{8}\right.$ to $\left.10^{9} \mathrm{CFU} / \mathrm{mL}\right)$ was diluted with sterile water to $1 \times 10^{5} \mathrm{CFU} / \mathrm{mL}$; then $50 \mu \mathrm{L}$ of diluted bacterial suspension was spread directly on each antibioticcontaining agar dilution plate. The inoculated culture medium was incubated at $30^{\circ} \mathrm{C}$. The MIC was defined as the lowest concentration at which no visible growth of $R$. solanacearum occurred after $48 \mathrm{~h}$ of inoculation. The MBC was defined as the lowest concentration at which no visible growth of $R$. solanacearum occurred after $96 \mathrm{~h}$ of inoculation. All assays were performed at least in triplicate.

\section{The Growth Curve of $R$. solanacearum}

The growth curve of $R$. solanacearum was investigated as in a previous study with minor modifications (Yang et al., 2017). Briefly, $125 \mu \mathrm{L}$ of overnight-cultured $R$. solanacearum suspension $\left(\mathrm{OD}_{600}=1.0\right)$ was added to $25 \mathrm{~mL}$ of $\mathrm{BG}$ medium supplemented with 7-methoxycoumarin to generate a final concentration of $10,25,50,75$, or $100 \mathrm{mg} / \mathrm{L}$. The control treatment was treated with $100 \mu \mathrm{L}$ of DMSO. Then, the triangular flask was incubated at $30^{\circ} \mathrm{C}$ for $24 \mathrm{~h}$. Bacterial density was determined by the optical density (OD) at $600 \mathrm{~nm}$ every $2 \mathrm{~h}$. Each treatment was repeated three times.

\section{Biofilm Formation Analysis}

The biofilm formation of $R$. solanacearum was carried out in 96-well polystyrene microtiter plates (Zhang et al., 2014). In short, BG medium and 7-methoxycoumarin were mixed in $5 \mathrm{~mL}$ sterilized centrifuge tubes to prepare $5,10,25,50$, and $100 \mathrm{mg} / \mathrm{L}$ concentration, and then $15 \mu \mathrm{L}$ of bacterial suspension $\left(\mathrm{OD}_{600}=1.0\right)$ cultured overnight was added to 96-well polystyrene microtiter plates and incubated without shanking for $24 \mathrm{~h}$ at $30^{\circ} \mathrm{C}$. The culture was removed carefully, and plates were washed twice with $200 \mu \mathrm{L}$ of distilled water. The 
biofilm was dyed by adding $220 \mu \mathrm{L}$ of crystal violet $(0.1 \%)$ and incubation at room temperature for $30 \mathrm{~min}$. After dyeing, the crystal violet was removed, and plates were washed twice with $200 \mu \mathrm{L}$ of distilled water. After removing the floating color, plates were dried at room temperature for $30 \mathrm{~min}$. Then, $200 \mu \mathrm{L}$ of 95\% ethanol was added to dissolve the crystal violet adsorbed on the biofilm for $30 \mathrm{~min}$, and the absorbance value at $530 \mathrm{~nm}$ was determined by a microplate reader, and this represented the biofilm formation of $R$. solanacearum under 7-methoxycoumarin treatment. Each treatment was repeated at least three times.

\section{Swimming Motility of $\boldsymbol{R}$. solanacearum Under 7-Methoxycoumarin Treatment}

The swimming motility of $R$. solanacearum was detected in semisolid medium as described in previous research (TansKersten et al., 2004). 7-methoxycoumarin was added to the semisolid motility medium to final concentrations of $10,25,50$, 75 , and $100 \mathrm{mg} / \mathrm{L}$. The bacterial suspension was diluted with sterile water to $\mathrm{OD}_{600}=0.1$, and $3 \mu \mathrm{L}$ of bacterial suspension was dropped onto the plate. The inoculated plate was incubated at $30^{\circ} \mathrm{C}$ without shaking. The diameter of the white zone around the colony was measured 24 and $48 \mathrm{~h}$ after inoculation. Each treatment was repeated three times.

\section{Transmission Electron Microscopy Analysis}

The morphological changes of $R$. solanacearum after 7methoxycoumarin treatment were further studied by electron microscopy, as in previous research with minor modifications (Chen et al., 2014). R. solanacearum $\left(\mathrm{OD}_{600}=1.0\right)$ suspension was evenly mixed with $37.5 \mathrm{mg} / \mathrm{L}$ 7-methoxycoumarin, and incubated at $30^{\circ} \mathrm{C}$ for $4-6 \mathrm{~h}$. After centrifuged at $8000 \mathrm{rpm}$ for $5 \mathrm{~min}$, the bacterial pellet was resuspended in $1 \mathrm{~mL}$ of sterilized deionized water, washed 3 times, and then fixed with $2.5 \%$ glutaraldehyde for $12 \mathrm{~h}$. Then, the bacterial pellet was dehydrated with $30,50,70,90$, and $100 \%$ ethanol of different gradient series for $15 \mathrm{~min}$, smoked with osmium acid for $3 \mathrm{~h}$ and observed directly under a scanning electron microscope. $R$. solanacearum cells were fixed with $1 \%$ aqueous OsO4 (Fluka, Los-Angeles, CA, United States) and washed with $0.1 \mathrm{M}, \mathrm{pH} 7.0$ phosphate buffers. Thin sections containing the cells were placed on copper grids and observed under a TEM (FEI, Brno, Czechia).

\section{RNA Extraction and Quantitative Real-Time RT-PCR}

The effect of 7-methoxycoumarin on the expression of virulenceassociated genes of $R$. solanacearum was evaluated as previously reported (Wu et al., 2015). Briefly, $250 \mu \mathrm{L}$ of the overnight cultured $R$. solanacearum suspension $\left(\mathrm{OD}_{600}=1.0\right)$ was added to $25 \mathrm{~mL}$ of $\mathrm{BG}$ medium, mixed with $1 / 2 \mathrm{MIC}(37.5 \mathrm{mg} / \mathrm{L})$ of 7-methoxycoumarin, and incubated at $30^{\circ} \mathrm{C}$ for $6-7 \mathrm{~h}$. The bacterial cells were collected by centrifugation, and the total RNA of $R$. solanacearum was extracted according to the TRIzol method. After CDNA was synthesized by reverse transcription, the key genes of the type III secretion system ( $r p p G$ and $p o p A)$, extracellular polysaccharide (epsE and $x p s R$ ), swimming motility $(v s r C)$, and chemotaxis (cheA and cheW) were selected for evaluation of gene expression levels. The primers of the tested genes used in this study were list in Supplementary Table 2 and the housekeeping gene serC was used as the control. RT-PCR was performed in a CFX96 Manager (Bio-Rad) using an Sso FastTM EvaGreen ${ }^{\circledR}$ Supermix (Bio-Rand, Hercules, CA, United States).

\section{Control Efficiency of 7-Methoxycoumarin on Tobacco Bacterial Wilt Under Greenhouse Conditions}

The naturalistic soil soak assay was used to evaluate the control efficiency of 7-methoxycoumarin on tobacco bacterial wilt as described in a previous study, with minor modifications (Wu et al., 2015). Briefly, unwounded, 6-week-old tobacco plants (Nicotiana tabacum. L Yunyan 87) were irrigated with $15 \mathrm{~mL}$ of 7-methoxycoumarin to a final concentration of 25,50 , and $100 \mathrm{mg} / \mathrm{g}$ soil. The same volume of $0.4 \%$ DMSO was used as a negative control, and as a thiadiazol copper with a final concentration of $100 \mathrm{mg} / \mathrm{L}$ was used as a positive control. After irrigation for $24 \mathrm{~h}$, individual plants were inoculated by pouring $10 \mathrm{~mL}$ of bacterial suspension into the soil to create a final inoculation density of $1 \times 10^{7} \mathrm{CFU} / g$ soil. Inoculated plants were placed in the climate room at $28^{\circ} \mathrm{C}$ with a $14 / 10 \mathrm{~h}$ light/dark cycle. The symptoms of each plant were scored daily using a disease index scale from 0 to 4 ( 0 , no symptoms appeared; $1,1-$ $25 \%$ of leaves wilted; $2,26-50 \%$ of leaves wilted; $3,51-75 \%$ of leaves wilted; 4 indicated $76-100 \%$ of leaves wilted). Individual treatments contained 12 plants for each independent experiment, and the assay was repeated three times. To determine the disease index and the control efficiency, we used the following formulas:

$$
\text { Disease index }=\frac{\sum(n i-v i)}{N \times 4} \times 100
$$

where, $n i=$ the number of plants with the respective disease index, $v i=$ disease index $(0,1,2,3$, and 4$)$, and $\mathrm{N}=$ the total number of plants used in each treatment.

$$
\text { Control efficiency }=\frac{(C K-T)}{C K} \times 100
$$

where, $\mathrm{T}=$ the disease index of treatment, and $\mathrm{CK}=$ the disease index of the control group.

\section{Statistical Analyses}

The data were analyzed with Excel 2010 and the SPSS17.0 statistical software program (SPSS Inc, Chicago, IL, United States) using Student's $t$-test and ANOVA under the significance level of 0.05, $0.01(P$-value $=0.05, P$-value $=0.01)$.

\section{RESULTS}

\section{MIC and MBC of 7-Methoxycoumarin Against $R$. solanacearum}

The minimal inhibitory concentration (MIC) and minimum bactericidal concentration $(\mathrm{MBC})$ of the pathogenic bacterium 

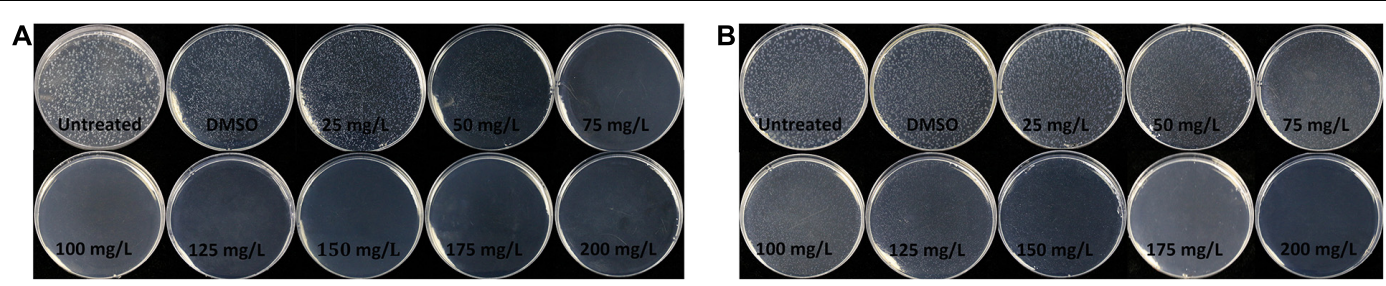

FIGURE 1 | The minimum inhibitory concentration (MIC) and minimal bactericidal concentration (MBC) of 7 -methoxycoumarin on $R$. solanacearum was determined using the agar dilution method at the concentrations ranging from 25 to $200 \mathrm{mg} / \mathrm{L}$. (A) $48 \mathrm{~h}$ after inoculation. (B) $96 \mathrm{~h}$ after inoculation.

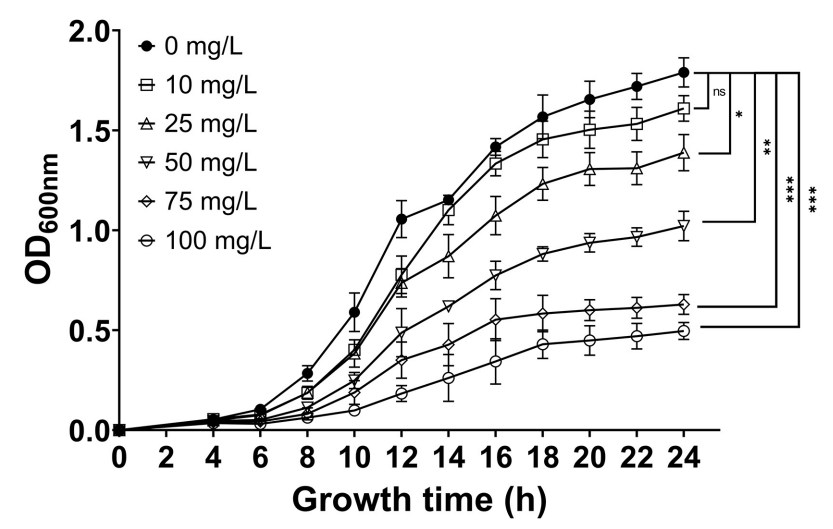

FIGURE 2 | The effect of 7-methoxycoumarin at concentrations ranging from 10 to $100 \mathrm{mg} / \mathrm{L}$ on the growth of $R$. solanacearum, $\left(^{*}\right.$ indicates $p<0.05$, ** indicates $p<0.01$, and ${ }^{* \star *}$ indicates $p<0.001$ ).

R. solanacearum were determined by the solid dilution method. As shown in Figure 1, the MIC and MBC of 7-methoxycoumarin were 75 and $175 \mathrm{mg} / \mathrm{L}$, respectively.

\section{7-Methoxycoumarin Inhibits the Growth of $R$. solanacearum}

Further investigation into the inhibitory effect of 7methoxycoumarin against $R$. solanacearum was performed. As shown in Figure 2, the growth of $R$. solanacearum was significantly inhibited at concentrations of 7-methoxycoumarin ranging from 25 to $100 \mathrm{mg} / \mathrm{L}$ and the antibacterial activity of 7-methoxycoumarin against $R$. solanacearum was concentrationdependent. As shown in Supplementary Table 1, the $\mathrm{IC}_{50}$ value of 7-methoxycoumarin was $52.98 \mathrm{mg} / \mathrm{L}$ after $24 \mathrm{~h}$ of culture.

\section{7-Methoxycoumarin Reduces the Biofilm Formation of $R$. solanacearum}

As shown in Figure 3, 7-methoxycoumarin significantly reduced the biofilm formation of $R$. solanacearum. The biofilm formation treated by DMSO was 0.59, significantly high than $R$. solanacearum supplemented with 25,50 , and $100 \mathrm{mg} / \mathrm{L}$ 7-methoxycoumarin, $\mathrm{OD}_{530 \mathrm{~nm}}$ were $0.43,0.42$, and 0.37 , respectively. Specifically, the inhibitory effects of 7-methoxycoumarin were 21.25, 23.20, and $28.76 \%$

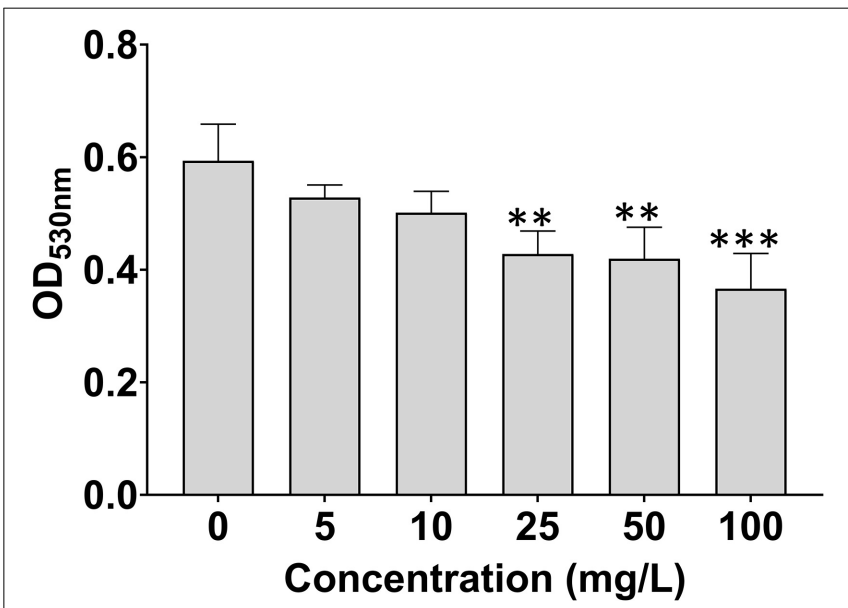

FIGURE 3 | Effects of 7-methoxycoumarin on biofilm formation of $R$. solanacearum. OD530 values were quantified after treatment with different concentrations of 7 -methoxycoumarin at $30^{\circ} \mathrm{C}$ for $24 \mathrm{~h}$ in 96 -well plates; ** indicates $p<0.01$ and ${ }^{* * *}$ indicates $p<0.001$ ).

at concentrations of 25, 50, and $100 \mathrm{mg} / \mathrm{L}$, respectively (Supplementary Figure 1).

As shown in Supplementary Figure 2, the swimming motility diameter of $R$. solanacearum 24 and $48 \mathrm{~h}$ after treatment with 7-methoxycoumarin was not different from that of the control treatment.

\section{The Effect of 7-Methoxycoumarin on the Cell Morphology of $\boldsymbol{R}$. solanacearum}

To further study the antibacterial mechanism of 7methoxycoumarin, the morphological changes of $R$. solanacearum after treatment with 7-methoxycoumarin were observed by SEM and TEM. As shown in Figure 4, negative control bacterial cells still maintain their integrity. In contrast, the surfaces of $R$. solanacearum after exposed to 7-methoxycoumarin (37.5 $\mathrm{mg} / \mathrm{L})$ were rough and obviously wrinkled. The damaged cell is also observed in TEM image as shown by the gray arrow in Figure 5, it is shown that 7-methoxycoumarin could damage or deconstruct cell walls to penetrate the bacterial cells, this damage may lead to the leakage of lysosomal contents resulting eventually in cell death. 

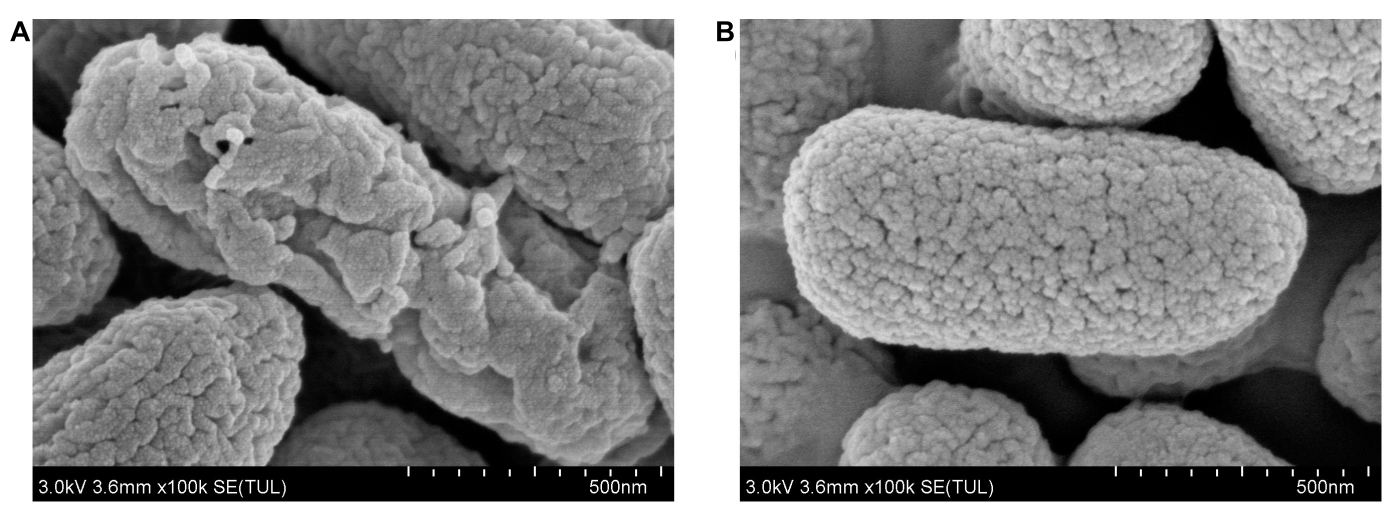

FIGURE 4 | SEM images of $R$. solanacearum cells treated with (A) 7-methoxycoumarin; (B) DMSO.
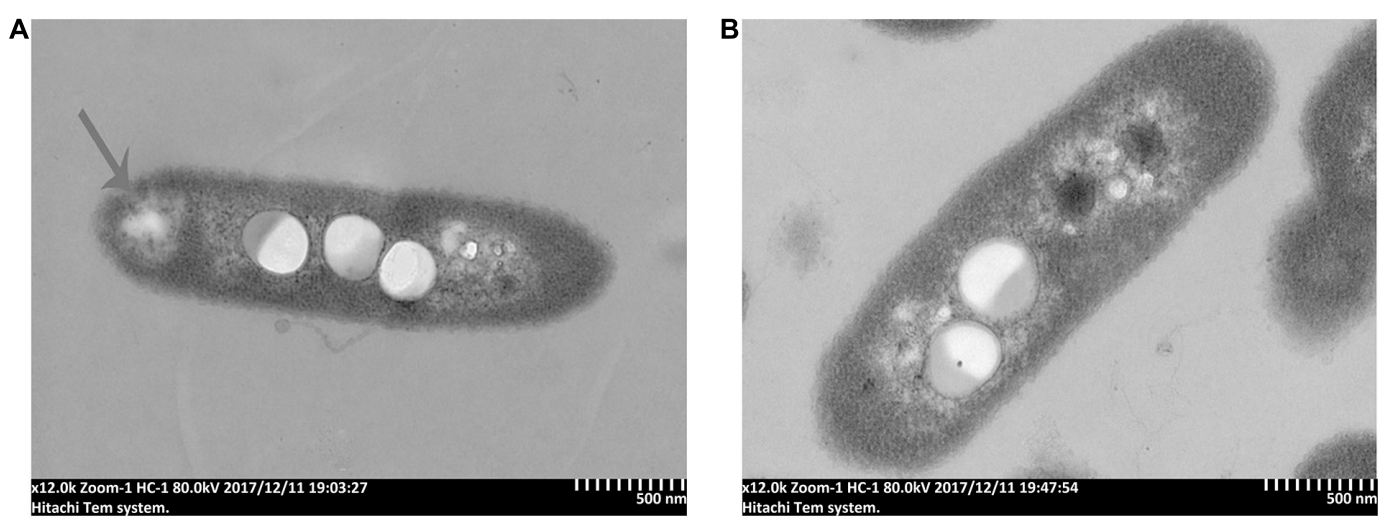

FIGURE 5 | TEM images of R. solanacearum cells treated with (A) 7-methoxycoumarin; (B) DMSO.

\section{7-Methoxycoumarin Suppresses the Expression of Virulence-Associated Genes in $R$. solanacearum}

In this study, qRT-PCR was used to evaluate the transcriptional expression of the major pathogenic genes of $R$. solanacearum treated with or without 7-methoxycoumarin. As shown in Figure 6, 7-methoxycoumarin inhibited the expression of type III secretion system associated-genes ( $p \circ p A$ and $h r p G)$ and the extracellular polysaccharide synthesis gene epsE. However, 7-methoxycoumarin was found to induce the expression of $v s r C$ and cheW. The results indicated that 7-methoxycoumarin can inhibit the genes of the type III secretory system and extracellular polysaccharides, demonstrated that this compound might has a certain preventive effect against host infection by R. solanacearum.

\section{Control Effect of 7-Methoxycoumarin on Tobacco Bacterial Wilt Disease}

Based on the strong antibacterial activity and biofilm formation inhibition of $R$. solanacearum by 7-methoxycoumarin, we examined the effect of irrigated roots with 7-methoxycoumarin on incidence of tobacco bacterial wilt. As shown in Figure 7A,

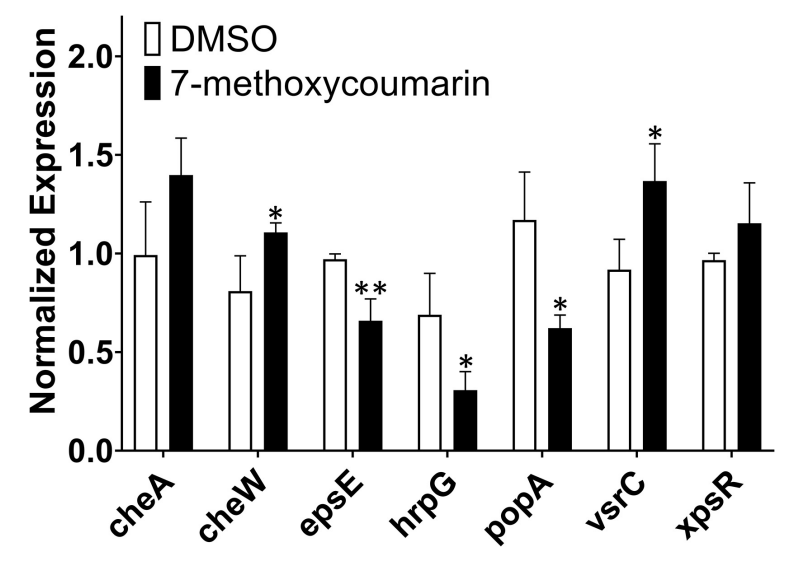

FIGURE 6 | The expression of some virulence-associated genes of $R$. solanacearum was quantified by qRT-PCR after treatment with or without 7 -methoxycoumarin ( ${ }^{*}$ indicates $p<0.05$ and ${ }^{* *}$ indicates $p<0.01$ ).

the disease index of DMSO treatment was 0.53, 2.03, 3.00, and 3.58 at $6,8,10$, and 12 days, respectively. Compared with DMSO, 7-methoxycoumarin treatments significantly altered the disease index of bacterial wilt and delayed plant 

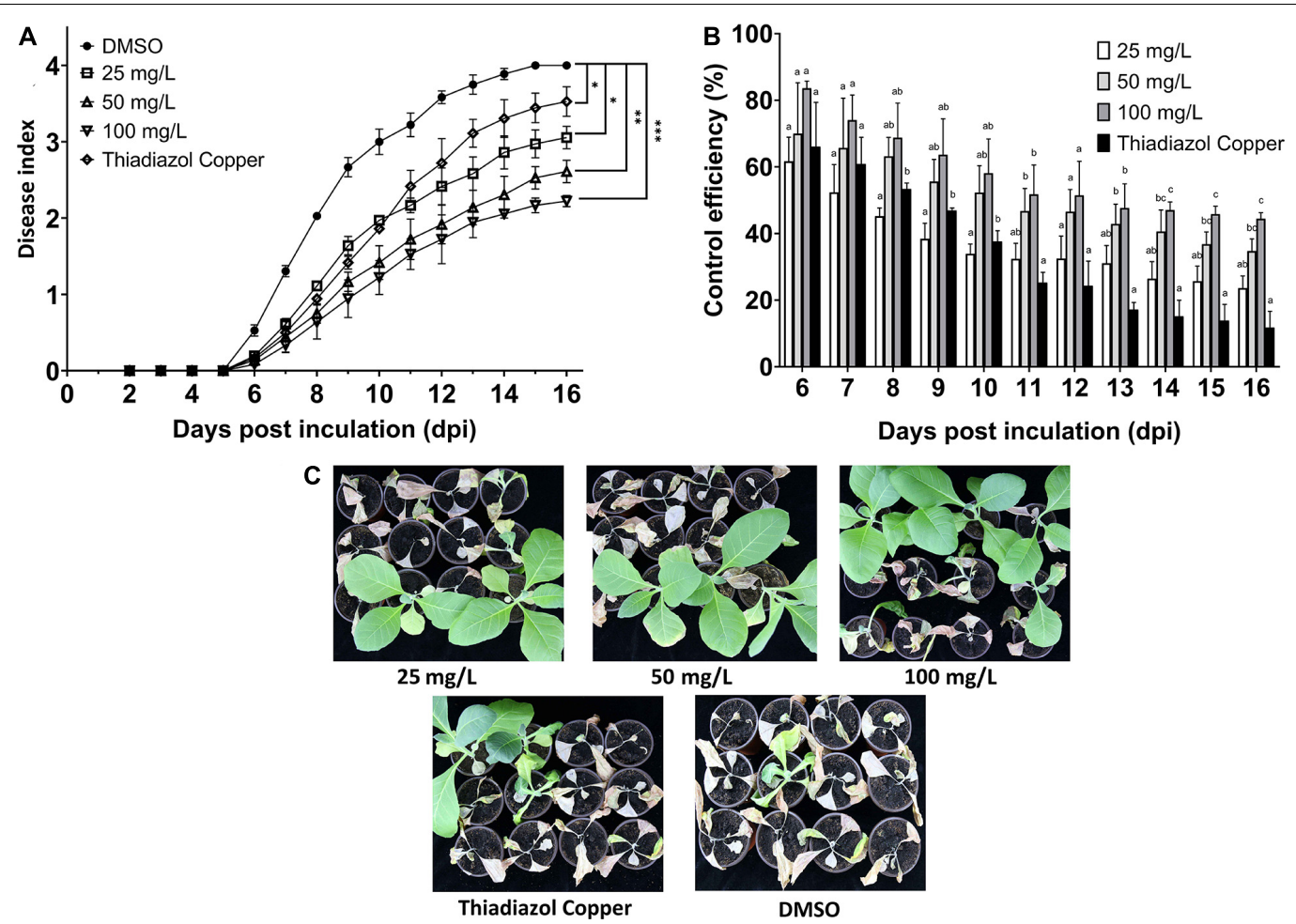

FIGURE 7 | Relative control effects of each treatment on pot experimental tobacco seedlings. (A):The disease index of tobacco wilt treated with 25,50 , and 100 mg/L 7-methoxycoumarin. (B) The control effect of 7-methoxycoumarin. (C) The control effect after 16 days of inoculation with R. solanacearum (* indicates $p<0.05,{ }^{\star \star}$ indicates $p<0.01$, and ${ }^{\star \star \star}$ indicates $\left.p<0.001\right)$. Different lowercase letters on the histogram of the same group indicate significant differences between different treatments, $p<0.05)$.

wilting. As shown in Figures 7B,C, 7-methoxycoumarin treatment at a concentration of $100 \mathrm{mg} / \mathrm{L}$ had control efficiencies of $83.61,68.78,58.11$, and $51.48 \%$ at 6,8 , 10 , and 12 days after inoculation, respectively, which significantly higher than the positive control treatment with $100 \mathrm{mg} / \mathrm{L}$ thiadiazol copper, with control efficiencies of $66.11,53.39,37.61$, and $24.37 \%$ at $6,8,10$, and 12 days, respectively.

\section{DISCUSSION}

Traditional chemical pesticides produce environmental pollution and cause damage to the human body during their use (Dasgupta et al., 2007; Acero et al., 2008). Because of their ecofriendly sources and non-toxicity to humans, PCDs have gradually come to be considered a new type of pesticide that can replace traditional chemical pesticides. It has been reported that lansiumamide $\mathrm{B}$, protocatechualdehyde and methyl gallate in PCDs have strong inhibitory effects on $R$. solanacearum to control the occurrence of tobacco bacterial wilt (Yuan et al., 2012; Fan et al., 2014; Wu et al., 2015). Previous studies show that hydroxycoumarins reduce the pathogenicity of $R$. solanacearum by suppressing T3SS and biofilm formation (Yang et al., 2018). However, the inhibitory activity of methoxycoumarins against
$R$. solanacearum, especially the mechanism of action, has not been reported.

This article is the first study of the antibacterial effect of 7-methoxycoumarin on $R$. solanacearum, and further elucidates its antibacterial mechanism. According to our results, 7methoxycoumarin inhibited the growth of $R$. solanacearum in both liquid medium and on solid medium (Figures 1, 2). Previous studies have identified phenyl derivatives as antimicrobial agents for the control of Pseudomonas aeruginosa, Bacilus subtillis and Xylella fastidiosa (Alam, 2004; Maddox et al., 2010). The antibacterial mechanism of phenolic compounds is similar to that of carvacrol and thymol, resulting in a change in membrane potential ( $\mathrm{Xu}$ et al., 2008). According to these observations, 7-methoxycoumarin caused ruffles and disruption to the cell membrane of $R$. solanacearum (Figures 4, 5). Previous reports indicate that 7-methoxycoumarin has an inhibitory effect on some gram-negative bacteria, including E. coli, V. cholerae, and Pneumococcus (Céspedes et al., 2006). Therefore, consideration of strong inhibition of $R$. solanacearum and environmental ecofriendly, 7-methoxycoumarin has great potential for application for plant disease control in the future.

As a plant secondary metabolite, coumarins have inhibitory activity against diverse plant diseases, including bacteria, fungi, and viruses (Goy et al., 1993). Several coumarins obtained from different plant species revealed strong antibacterial activity against human associated E. coli, S. aureus, and P. aeruginosa 
(Khan et al., 2010; Gnonlonfin et al., 2012). The young leaves of $N$. attenuata exhibited an increased resistance to A. alternata, which is associated with scopoletin accumulation (Sun et al., 2014). When Arabidopsis was infected by Pythium sylvaticum, scopolamine was utilized to synthesize a huge number of inhibitory substances-scopoletin, which concentrated at sites of infestation to inhibit the normal growth of Phytophthora (Bednarek et al., 2005). Recently, it was proven that scopoletin induces the accumulation of reactive oxygen species (ROS) such as $\mathrm{H}_{2} \mathrm{O}_{2}$ and $\mathrm{O}^{2-}$, which prevents Asian soybean rust from infecting Arabidopsis (Beyer et al., 2019). Coumarins might act as plant antibacterial agents or immunity elicitors, which plays an important role in plant defense.

Like many plant pathogens, $R$. solanacearum forms biofilmlike aggregates in the roots of host plants, leading to bacterial invasion and infection (Yao and Allen, 2007). Studies have found that coumarins, such as scopoletin, umbelliferone, daphnetin, and esculetin, are secreted by plants to protect themselves from the attack of pathogens (Kai et al., 2006). In this study, 7methoxycoumarin significantly inhibited the biofilm formation of $R$. solanacearum, but had no significant effect on the swimming motility of $R$. solanacearum (Figure 3 and Supplementary Figure 1). We speculated that 7-methoxycoumarin is more likely to reduce host infection by $R$. solanacearum via affecting biofilm formation. Nevertheless, further elucidation of this mode of action may need a more systematic study of the relationship between 7-methoxycoumarin, $R$. solanacearum, and host plants.

Genes related to $R$. solanacearum pathogenicity have been comprehensively and thoroughly studied. For example, type III secretion system genes $h r p G$ and popA are involved in the regulation of bacterial infection by $R$. solanacearum (Belbahri et al., 2001; Liu et al., 2014). The results of this study showed that 7-methoxycoumarin significantly inhibited the expression of $h r p G$ and $p o p A$, but had little effect on the expression of cheA and $x p s R$. These results indicated 7-methoxycoumarin might suppress type III secretion system and biofilm formation of $R$. solanacearum. Further studies should be explained the effect of 7-methoxycoumarin on popA.

The control effect of the $100 \mathrm{mg} / \mathrm{L}$ 7-methoxycoumarin treatment on tobacco bacterial wilt was not significantly different from that of the control agent thiadiazol copper in the early stage of the disease, but the lasting time was better than that of thiadiazol copper, and the control effect in the later stage of the disease could still reach to $44.44 \%$. Although 7 -methoxycoumarin has shown potential as an effective plant-derived antibacterial agent against bacterial wilt, it is not clear whether this effect can be sustained in different field environments.

In conclusion, 7-methoxycoumarin is a potential antibacterial agent in plants, which is more likely to act as a crucial remedy for future field applications for bacterial wilt. Exposure

\section{REFERENCES}

Abo-Elyousr, K. A., Seleim, M. A., Abd-El-Moneem, K. M., and Saead, F. A. (2014). Integrated effect of Glomus mosseae and selected plant oils on the control of bacterial wilt disease of tomato. Crop Protect. 66, 67-71. doi: 10.1016/j.cropro. 2014.07.022 to 7-methoxycoumarin could protect tobacco plants against $R$. solanacearum by strongly inhibiting biofilm formation, and killing the bacteria. Therefore, our study provides environmentally friendly and effective tactics for the research and development of tobacco bacterial wilt control agents and might be extended to the application of other plant disease control in the future.

\section{CONCLUSION}

In summary, a new plant-derived compound, 7methoxycoumarin, exhibited strong antibacterial activity against $R$. solanacearum. 7-Methoxycoumarin significantly inhibited biofilm formation and induced bacterial cell membrane lysis. Virulence-associated genes epsE, $h r p G$, and $p o p A$ were significantly suppressed by 7 -methoxycoumarin. Finally, the new antibacterial agent 7-methoxycoumarin suppressed tobacco bacterial wilt progress and lead to better control effect on tobacco bacterial wilt. This study suggests that 7-methoxycoumarin has potential application in the control of plant bacterial wilt and other plant diseases in the future.

\section{DATA AVAILABILITY STATEMENT}

The raw data supporting the conclusions of this article will be made available by the authors, without undue reservation.

\section{AUTHOR CONTRIBUTIONS}

WD and LY conceived and designed the experiments. SH, LY, YW, and YR performed the experiments. SH, LY, and SL analyzed the data. SH, WD, and LY wrote the article. All authors contributed to the article and approved the submitted version.

\section{FUNDING}

This work was supported by the National Natural Science Foundation of China (31972288) and the key project of the China National Tobacco Corporation (110201901042).

\section{SUPPLEMENTARY MATERIAL}

The Supplementary Material for this article can be found online at: https://www.frontiersin.org/articles/10.3389/fmicb. 2021.697911/full\#supplementary-material

Acero, J. L., Benitez, F. J., Real, F. J., and González, M. (2008). Chlorination of organophosphorus pesticides in natural waters. J. Hazardous Mater. 153, 320-328. doi: 10.1016/j.jhazmat.2007.08.051

Alam, S. (2004). Synthesis, antibacterial and antifungal activity of some derivatives of 2-phenyl-chromen-4-one. J. Chem. Sci. 116, 325-331. doi: 10.1007/ BF02711433 
Bai, W., Kong, F., Lin, Y., and Zhang, C. (2016). Extract of Syringa oblata: a new biocontrol agent against tobacco bacterial wilt caused by Ralstonia solanacearum. Pesticide Biochem. Physiol. 134, 79-83. doi: 10.1016/j.pestbp. 2016.04.002

Bednarek, P., Schneider, B., Svatoš, A., Oldham, N. J., and Hahlbrock, K. (2005). Structural complexity, differential response to infection, and tissue specificity of indolic and phenylpropanoid secondary metabolism in Arabidopsis roots. Plant Physiol. 138, 1058-1070. doi: 10.1104/pp.104.057794

Belbahri, L., Boucher, C., Candresse, T., Nicole, M., Ricci, P., and Keller, H. (2001). A local accumulation of the Ralstonia solanacearum PopA protein in transgenic tobacco renders a compatible plant-pathogen interaction incompatible. Plant $J$. 28, 419-430. doi: 10.1046/j.1365-313X.2001.01155.x

Beyer, S. F., Beesley, A., Rohmann, P. F. W., Schultheiss, H., Conrath, U., and Langenbach, C. J. G. (2019). The Arabidopsis non-host defence-associated coumarin scopoletin protects soybean from Asian soybean rust. Plant J. 99, 397-413. doi: 10.1111/tpj.14426

Boucher, C. A., Barberis, P. A., Trigalet, A. P., and Demery, D. A. (1985). Transposon mutagenesis of Pseudomonas solanacearum: isolation of Tn5induced avirulent mutants. Microbiology 131, 2449-2457. doi: 10.1099/ 00221287-131-9-2449

Cai, L., Chen, J., Liu, Z., Wang, H., Yang, H., and Ding, W. (2018). Magnesium oxide nanoparticles: effective agricultural antibacterial agent against Ralstonia solanacearum. Front. Microbiol. 9:790. doi: 10.3389/fmicb.2018.00790

Cai, L., Zhang, W., Jia, H., Feng, H., Wei, X., Chen, H., et al. (2020). Plant-derived compounds: a potential source of drugs against Tobacco mosaic virus. Pesticide Biochem. Physiol. 169:104589. doi: 10.1016/j.pestbp.2020.104589

Céspedes, C. L., Avila, J. G., Martínez, A., Serrato, B., Calderón-Mugica, J. C., Salgado-Garciglia, R., et al. (2006). Antifungal and antibacterial activities of Mexican tarragon (Tagetes lucida). J. Agric. 54, 3521-3527. doi: 10.1021/ jf053071w

Chen, J., Peng, H., Wang, X., Shao, F., Yuan, Z., and Han, H. (2014). Graphene oxide exhibits broad-spectrum antimicrobial activity against bacterial phytopathogens and fungal conidia by intertwining and membrane perturbation. Nanoscale 6, 1879-1889. doi: 10.1039/c3nr04941h

Chen, J., Yu, Y., Li, S., and Ding, W. (2016). Resveratrol and coumarin: novel agricultural antibacterial agent against Ralstonia solanacearum in vitro and in vivo. Molecules 21:1501. doi: 10.3390/molecules21111501

Dasgupta, S., Meisner, C., Wheeler, D., Xuyen, K., and Lam, N. T. (2007). Pesticide poisoning of farm workers-implications of blood test results from Vietnam. Int. J. Hygiene Environ. Health 210, 121-132. doi: 10.1016/j.ijheh.2006.08.006

Fan, W., Yuan, G., Li, Q., and Lin, W. (2014). Antibacterial mechanisms of methyl gallate against Ralstonia solanacearum. Austr. Plant Pathol. 43, 1-7. doi: 10. 1007/s13313-013-0234-y

Fujiwara, A., Fujisawa, M., Hamasaki, R., Kawasaki, T., Fujie, M., and Yamada, T. (2011). Biocontrol of Ralstonia solanacearum by treatment with lytic bacteriophages. Appl. Environ. Microbiol. 77, 4155-4162. doi: 10.1128/AEM. 02847-10

Gnonlonfin, G. B., Sanni, A., and Brimer, L. (2012). Review scopoletin-a coumarin phytoalexin with medicinal properties. Crit. Rev. Plant Sci. 31, 47-56. doi: 10.1080/07352689.2011.616039

Goy, P. A., Signer, H., Reist, R., Aichholz, R., Blum, W., Schmidt, E., et al. (1993). Accumulation of scopoletin is associated with the high disease resistance of the hybrid Nicotiana glutinosa x Nicotiana debneyi. Planta 191, 200-206. doi: 10.1007/BF00199750

Guo, B., Zhang, Y., Li, S., Lai, T., Yang, L., Chen, J., et al. (2016). Extract from Maize (Zea mays L.): antibacterial activity of DIMBOA and Its derivatives against Ralstonia solanacearum. Molecules 21:1397. doi: 10.3390/molecules21101397

Gutiérrez-Barranquero, J. A., de Vicente, A., Carrión, V. J., Sundin, G. W., and Cazorla, F. (2013). Recruitment and rearrangement of three different genetic determinants into a conjugative plasmid increase copper resistance in Pseudomonas syringae. Appl. Environ. Microbiol. 79, 1028-1033. doi: 10.1128/ AEM.02644-12

Hassan, M., Bereika, M., Abo-Elnaga, H., and Sallam, M. (2009). Direct antimicrobial activity and induction of systemic resistance in potato plants against bacterial wilt disease by plant extracts. Plant Pathol. J. 25, 352-360. doi: 10.5423/PPJ.2009.25.4.352
Jiang, G., Wei, Z., Xu, J., Chen, H., Zhang, Y., She, X., et al. (2017). Bacterial wilt in China: history, current status, and future perspectives. Front. Plant Sci. 8:1549. doi: 10.3389/fpls.2017.01549

Kai, K., Shimizu, B.-i, Mizutani, M., Watanabe, K., and Sakata, K. (2006). Accumulation of coumarins in Arabidopsis thaliana. Phytochemistry 67, 379386. doi: 10.1016/j.phytochem.2005.11.006

Kayser, O., and Kolodziej, H. (1999). Antibacterial activity of simple coumarins: structural requirements for biological activity. Zeitschr. Für Naturforschung $C$ 54, 169-174. doi: 10.1515/ZNC-1999-3-405

Khan, R., Bhat, K. A., Raja, A. F., Shawl, A. S., and Alam, M. S. (2010). Isolation, characterisation and antibacterial activity studies of coumarins from Rhododendron lepidotum Wall. ex G. Don, Ericaceae. Rev. Brasil. Farmacognosia 20, 886-890. doi: 10.1590/S0102-695X2010005000037

Khokhani, D., Zhang, C., Li, Y., Wang, Q., Zeng, Q., Yamazaki, A., et al. (2013). Discovery of plant phenolic compounds that act as type III secretion system inhibitors or inducers of the fire blight pathogen, Erwinia amylovora. Appl. Environ. Microbiol. 79, 5424-5436. doi: 10.1128/AEM.00845-13

Li, L., Feng, X., Tang, M., Hao, W., Han, Y., Zhang, G., et al. (2014). Antibacterial activity of Lansiumamide B to tobacco bacterial wilt (Ralstonia solanacearum). Microbiol. Res. 169, 522-526. doi: 10.1016/j.micres.2013.12.003

Li, S., Liu, Y., Wang, J., Yang, L., Zhang, S., Xu, C., et al. (2017). Soil acidification aggravates the occurrence of bacterial wilt in South China. Front. Microbiol. 8:703. doi: $10.3389 /$ fmicb. 2017.00703

Li, S., Yu, Y., Chen, J., Guo, B., Yang, L., and Ding, W. (2016). Evaluation of the antibacterial effects and mechanism of action of Protocatechualdehyde against Ralstonia solanacearum. Molecules 21:754. doi: 10.3390/molecules210 60754

Li, Y., Hutchins, W., Wu, X., Liang, C., Zhang, C., Yuan, X., et al. (2015). Derivative of plant phenolic compound inhibits the type III secretion system of D ickeya dadantii via HrpX/HrpY two-component signal transduction and Rsm systems. Mol. Plant Pathol. 16, 150-163. doi: 10.1111/mpp.12168

Liu, Y., Tang, Y., Qin, X., Yang, L., Jiang, G., Li, S., et al. (2017). Genome sequencing of Ralstonia solanacearum CQPS-1, a phylotype I strain collected from a highland area with continuous cropping of tobacco. Front. Microbiol. 8:974. doi: 10.3389/fmicb.2017.00974

Liu, Z., Zou, L., Xue, X., Cai, L., Ma, W., Xiong, L., et al. (2014). HrcT is a key component of the type III secretion system in Xanthomonas spp. and also regulates the expression of the key hrp transcriptional activator HrpX. Appl. Environ. Microbiol. 80, 3908-3919. doi: 10.1128/AEM.00308-14

Maddox, C. E., Laur, L. M., and Tian, L. (2010). Antibacterial activity of phenolic compounds against the phytopathogen Xylella fastidiosa. Curr. Microbiol. 60:53. doi: 10.1007/s00284-009-9501-0

Paret, M. L., Cabos, R., Kratky, B., and Alvarez, A. M. (2010). Effect of plant essential oils on Ralstonia solanacearum race 4 and bacterial wilt of edible ginger. Plant Dis. 94, 521-527. doi: 10.1094/PDIS-94-5-0521

Shew, A. M., Durand-Morat, A., Nalley, L. L., Zhou, X.-G., Rojas, C., and Thoma, G. (2019). Warming increases Bacterial Panicle Blight (Burkholderia glumae) occurrences and impacts on USA rice production. PLoS One 14:e0219199. doi: 10.1371/journal.pone.0219199

Souza, S. M. d, Monache, F. D., and Smânia, A. (2005). Antibacterial activity of coumarins. Zeitschr. Naturforschung C 60, 693-700. doi: 10.1515/znc-2005-91006

Sun, H., Wang, L., Zhang, B., Ma, J., Hettenhausen, C., Cao, G., et al. (2014). Scopoletin is a phytoalexin against Alternaria alternata in wild tobacco dependent on jasmonate signalling. J. Exp. Bot. 65, 4305-4315. doi: 10.1093/ jxb/eru203

Swanson, J. K., Yao, J., Tans-Kersten, J., and Allen, C. (2005). Behavior of Ralstonia solanacearum race 3 biovar 2 during latent and active infection of geranium. Phytopathology 95, 136-143. doi: 10.1094/PHYTO-95-0136

Tans-Kersten, J., Brown, D., and Allen, C. (2004). Swimming motility, a virulence trait of Ralstonia solanacearum, is regulated by FlhDC and the plant host environment. Mol. Plant Microbe Interact. 17, 686-695. doi: 10.1094/MPMI. 2004.17.6.686

Wu, D., Ding, W., Zhang, Y., Liu, X., and Yang, L. (2015). Oleanolic acid induces the type III secretion system of Ralstonia solanacearum. Front. Microbiol. 6:1466. doi: $10.3389 /$ fmicb.2015.01466 
Xu, J., Zhou, F., Ji, B. P., Pei, R. S., and Xu, N. (2008). The antibacterial mechanism of carvacrol and thymol against Escherichia coli. Lett. Appl. Microbiol. 47, 174-179. doi: 10.1111/j.1472-765X.2008.02407.x

Yang, L., Li, S., Qin, X., Jiang, G., Chen, J., Li, B., et al. (2017). Exposure to umbelliferone reduces Ralstonia solanacearum biofilm formation, transcription of type III secretion system regulators and effectors and virulence on tobacco. Front. Microbiol. 8:1234. doi: 10.3389/fmicb.2017.01234

Yang, L., Wu, L., Yao, X., Zhao, S., Wang, J., Li, S., et al. (2018). Hydroxycoumarins: New, effective plant-derived compounds reduce Ralstonia pseudosolanacearum populations and control tobacco bacterial wilt. Microbiol. Res. 215, 15-21. doi: 10.1016/j.micres.2018.05.011

Yao, J., and Allen, C. (2007). The plant pathogen Ralstonia solanacearum needs aerotaxis for normal biofilm formation and interactions with its tomato host. J. Bacteriol. 189, 6415-6424. doi: 10.1128/JB.00398-07

Yuan, G., Li, Q., Qin, J., Ye, Y., and Lin, W. (2012). Isolation of methyl gallate from Toxicodendron sylvestre and its effect on tomato bacterial wilt. Plant Dis. 96, 1143-1147. doi: 10.1094/PDIS-03-11-0150-RE

Zeid, A. H. S. A. (2002). Stress metabolites from Corchorus olitorius L. leaves in response to certain stress agents. Food Chem. 76, 187-195. doi: 10.1016/S03088146(01)00264-3
Zhang, L., Xu, J., Xu, J., Zhang, H., He, L., and Feng, J. (2014). TssB is essential for virulence and required for type VI secretion system in Ralstonia solanacearum. Microb. Pathog. 74, 1-7. doi: 10.1016/j.micpath.2014.06.006

Conflict of Interest: The authors declare that the research was conducted in the absence of any commercial or financial relationships that could be construed as a potential conflict of interest.

Publisher's Note: All claims expressed in this article are solely those of the authors and do not necessarily represent those of their affiliated organizations, or those of the publisher, the editors and the reviewers. Any product that may be evaluated in this article, or claim that may be made by its manufacturer, is not guaranteed or endorsed by the publisher.

Copyright $\odot 2021$ Han, Yang, Wang, Ran, Li and Ding. This is an open-access article distributed under the terms of the Creative Commons Attribution License (CC BY). The use, distribution or reproduction in other forums is permitted, provided the original author(s) and the copyright owner(s) are credited and that the original publication in this journal is cited, in accordance with accepted academic practice. No use, distribution or reproduction is permitted which does not comply with these terms. 